\title{
Cellulose hollow fibers for organic resistant nanofiltration
}

\author{
Gheorghe Falca $^{\mathrm{a}}$, Valentina-Elena Musteata ${ }^{\mathrm{a}}$, Ali Reza Behzad ${ }^{\mathrm{b}}$, Stefan Chisca ${ }^{\mathrm{a}}$, \\ and Suzana Pereira Nunes ${ }^{\mathrm{a}}$
}

${ }^{a}$ King Abdullah University of Science and Technology (KAUST), Biological and Environmental Science and Engineering Division, Advanced Membranes and Porous Materials Center, 23955-6900 Thuwal, Saudi Arabia

${ }^{b}$ King Abdullah University of Science and Technology (KAUST), Advanced Nanofabrication Imaging and Characterization Laboratory, 23955-6900 Thuwal, Saudi Arabia

Corresponding author:

Suzana P. Nunes, suzana.nunes@kaust.edu.sa 


\section{Graphical abstract}

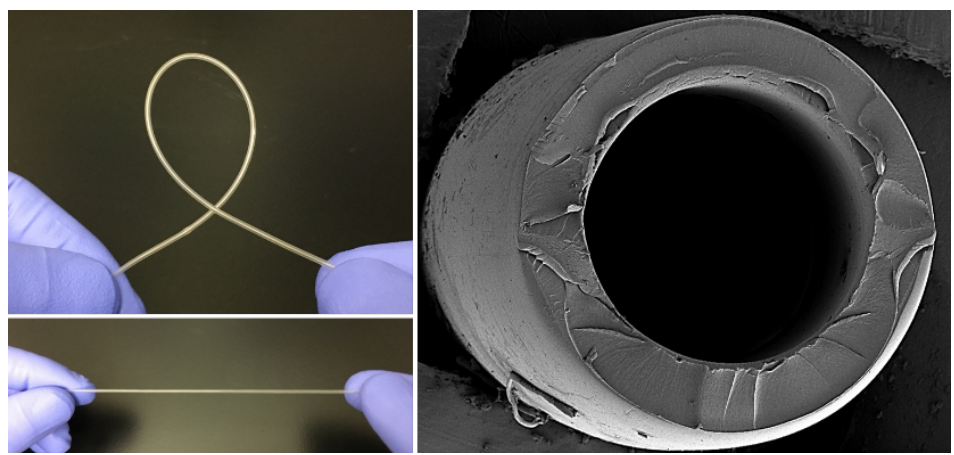

Easy-handling hollow fiber images and their corresponding cryo-scanning electron microscopy image. 


\begin{abstract}
Cellulose is the most abundant biopolymer, but it is difficult to process due to its low solubility in most of the solvents. In this work, we demonstrate the preparation, of self-standing and defect-free cellulose hollow fiber membranes made by a sustainable process for filtration in organic solvent medium. The hollow fibers were made by the simple spinning technique using ionic liquids as a solvent. The spun solutions were prepared with three different ionic liquids, having imidazoliumbased cations and acetate or phosphates as anions. We used X-ray diffraction to evaluate the influence of the different ionic liquids on the crystallinity of the cellulose and the membrane solvent stability. We used cryo-scanning electron microscopy to investigate the porous structure of the hydrated membranes, distinguishing it from that of the dry membranes. The hollow fiber membrane performance was studied using dyes in water and ethanol solutions. The rejection of Congo Red (696 g/mol) was higher than $90 \%$ in ethanol and even closer to $100 \%$ in water. The best results were obtained by using 1-ethyl-3-methyimidazolium diethyl phosphate and 1,3dimethylimidazolium dimethyl phosphate. Our results indicate that by using greener process is possible to obtain solvent resistant cellulose hollow fibers.
\end{abstract}

Keywords: cellulose, hollow fibers, ionic liquids, organic solvent resistant membranes 


\section{Introduction}

The demand for natural materials steadily increases due to their biocompatibility and greener manufacturing features [1]. Cellulose stands out as the major biopolymer naturally produced during the plant growth. Additionally, it may also be generated by a bacterial metabolism through in-situ production and easily disposed via enzymatic saccharification [2, 3]. Cellulose can be used for several applications such as liquid or gas separation, as fibers, nanocrystals, reinforcement nanofibrils, and as raw material for biofuel [4-7]. Despite its several advantages, only a small percentage is nowadays used in industries such as paper, textile, and pharmaceutical [7]. The cellulose structure is complex, constituted by coexisting crystalline and amorphous regions with strong hydrogen bonds, with different spatial arrangements or polymorphs. Six different polyforms are currently known, and they strongly depend on the nature of the cellulose itself. The most common are cellulose I and cellulose II. The first one is found in the native cellulose and leads to higher crystallinity degree, but is the thermodynamically least stable. Cellulose II instead, besides having more stability, is reported to be the most spread, since it arises from the dissolutionregeneration and mercerization of the biopolymer [8-10].

The cellulose macromolecule is formed by several subunits of D-glucose. Each one of them possesses three hydroxyl groups, which make the chemical modification very appealing, but at the same time make the cellulose quite challenging to dissolve. In fact, the hydroxy groups are positioned on the ring plane, while the hydrogen atoms are vertically directed, and together can form inter and intramolecular hydrogen bonds, from which, the final hierarchical structure arises [11]. This complexity is one of the discussed causes of dissolution problems in the most common solvents. Although cellulose is overall a hydrophilic molecule, it has an amphiphilic character, and to be solubilized, the solvent has to overcome both hydrophilic and hydrophobic interactions; in other words, an amphiphilic solvent is needed [11-13]. The most spread dissolution methods in the industry involve the use of acids [14, 15], alkali [16], or organic solvents [17] with dissolved salts [18-20], which as well, might chemically modify the cellulose. A more compressive and detailed solvent list is reported elsewhere [21, 22]. Most of the mentioned processes are environmentally hostile and consider a large amount of solvent waste. Moreover, a significant part of the operating cost in the industry is reported to be related to solvents consumption, and/or disposal [23-25]. 
Therefore, an alternative and greener method should be industrially adopted to dissolve the biopolymer.

The harsh more commonly used solvents for cellulose can be substituted by ionic liquids (IL) [26], which are organic salts with negligible vapor pressure; this is a crucial parameter since one of the major pollutions causes nowadays is due to the vapor organic compounds (VOC) [27]. Additionally, it is possible to adjust the sizes of the cation and the anion forming the IL, giving the possibility to tune the hydrophilicity/hydrophobicity of the solvent $[28,29]$. The first dissolution of cellulose with ionic liquids is documented in a patent of 1934 [30], and a long time has passed before this concept turned into a real application. Nowadays many systems based on different combinations of anion/cations are reported [31-35]. One of the fields that could profit more from the dissolution of cellulose in ILs is the membrane technology and efforts in flat-sheet membrane preparation using ILs are now reported [6, 36-41]. Different rejection level has also been achieved, varying from the ultrafiltration (UF) to the nanofiltration (NF) field. So far, the reports on cellulose membranes prepared from solutions in ionic liquids have focused on flat sheet membrane configurations [42], while the more challenging and appealing hollow fiber preparation for nanofiltration application has been explored yet. Cellulose hollow fibers were previously spun only in common solvents $[17,43,44]$ for gas separations and UF purpose.

Although cellulose membranes prepared by simple phase inversion in water apparently lead to a dense morphology [10], the transport of small molecules is promoted by differential interactions between the cellulose and the solute molecules, which are predominantly based on hydrogen bonds. The characteristics of cellulose membranes make them suitable for dyes separations. Dyes are widely used in the rubber, textile, pharmaceutical, and petroleum industries. However, some of them are found to be linked to health disorder and, in some cases, they might even be mutagenic [45]. Moreover, in the textile processing, besides high quantities of produced wastewater containing dyes, also organic solvents are present. A solvent recovery using nanofiltration or adsorption technologies would be a good solution for the waste reduction [46-48]. The process of organic solvent nanofiltration (OSN) [49] typically aims to separate molecules with size in the range of 200 to $1000 \mathrm{~g} \mathrm{~mol}^{-1}$ [50], which includes most of the dyes.

The development of solvent resistant membranes is growing fast, using materials such as poly(ether ether ketone) (PEEK) [51, 52], polyimide (PI) [53-55], polybenzimidazole (PBI) [56, 57] and polytriazole (PTA) [58, 59]. In most cases, the solvent resistance is only achieved by 
crosslinking. Otherwise, non-crosslinked membranes suitable for use in organic solvents are commonly processed by using acids or other aggressive solvents.

In this work, we propose and demonstrate the manufacture of cellulose hollow fibers by the simple spinning procedure, using three different ionic liquids as solvent. The selectivity for different dyes and their affinity to the membrane have been investigated by dynamic filtration and static adsorption using organic solvents and water. Effective solvent resistant nanofiltration membranes could be obtained without the necessity of a crosslinking reaction.

\section{Experimental}

\subsection{Materials}

Cellulose Avicel PH-101, 1-ethyl-3-metthylimidazolium acetate ([EMIM][Ac]), 1-ethyl-3methyimidazolium diethyl phosphate ([EMIM][DEP]), 1,3-dimethylimidazolium dimethyl phosphate ([DMIM][DMP]), 1-ethyl-3-methylimidazolium chloride ([EMIM][Cl]), ethanol (99.9\%), acetone (99\%), methanol (99\%), dimethylformamide (DMF) (99.8\%), tetrahydrofuran (THF) (99\%), N-methyl-2-pyrrolydone (NMP) (99.5\%), glycerol (99.5\%), Congo Red (CR),

Safranin O (S), Brilliant Blue R (BBR), Reactive Green (RG), polyethylene glycol (PEG) (0.4, $1.5,10$ and $35 \mathrm{~kg} / \mathrm{mol})$ and polystyrene (PS)(2, 10 and $30 \mathrm{~kg} / \mathrm{mol})$ were purchased from SigmaAldrich and used without further purification.

\subsection{Preparation of cellulose membranes}

The pristine cellulose was firstly dried in a vacuum oven at $70^{\circ} \mathrm{C}$ for $3 \mathrm{~h}$ to eliminate the residual moisture. Flat-sheet and hollow fiber cellulose membranes were prepared using the dried pristine polymer dissolved in the ionic liquids listed in Table 1. The flat-sheet free-standing membranes were obtained by casting $12 \mathrm{wt} \%$ solutions on glass plates at $80^{\circ} \mathrm{C}$, followed by immersion in water. A $12 \mathrm{wt} \%$ cellulose dope was also used to spin hollow fibers in a small laboratory spinning apparatus under the conditions listed in Table 1. The solutions were vigorously stirred for about 2 days at $85^{\circ} \mathrm{C}$. The homogeneous viscous solution was transferred to a previously heated metallic container. The pre-heating was essential to avoid any gelation. The container was coiled up with electrical heaters. The solution was degassed at $90^{\circ} \mathrm{C}$ overnight. The container was connected to a nitrogen cylinder and the spinneret. The fibers were obtained by spinning, reaching the non- 
solvent bath by free-falling. The hollow fibers were kept in the water bath for 2 days to guarantee that the solvent was washed out. Finally, the membranes were immersed in an aqueous glycol solution before drying to avoid any pore collapse. The hollow fiber modules were prepared with a single fiber. A pair of Swagelok t- connections were mounted on a straight tube; then the fiber was threaded through it and fixed with epoxy resin. 
Table 1. Casting and spinning conditions for cellulose flat-sheet membranes and hollow fiber preparation

$\begin{aligned} & \text { Operating } \\ & \text { conditions }\end{aligned}$
[EMIM][Ac]

Flat-sheet preparation conditions

Casting

temperature

$\left({ }^{\circ} \mathrm{C}\right)$

Hollow Fiber Spinning Conditions

\begin{tabular}{|c|c|c|c|}
\hline $\begin{array}{l}\text { External } \\
\text { coagulant }\end{array}$ & Tap water & Tap water & Tap water \\
\hline Bore fluid & DI water & DI water & DI water \\
\hline $\begin{array}{l}\text { Bore fluid flow } \\
\text { rate }(\mathrm{ml} / \mathrm{min})\end{array}$ & 4 & 4 & 4 \\
\hline Air gap (cm) & 20 & 20 & 20 \\
\hline $\begin{array}{l}\text { Dope solution } \\
\text { and spinneret } \\
\text { temperature } \\
(\circ \mathrm{C})\end{array}$ & 90 & 90 & 90 \\
\hline $\begin{array}{l}\text { External } \\
\text { coagulant } \\
\text { temperature } \\
(\circ \mathrm{C})\end{array}$ & 25 & 25 & 25 \\
\hline $\begin{array}{l}\text { Spinning } \\
\text { pressure (bar) }\end{array}$ & 3 & 3 & 3 \\
\hline
\end{tabular}




\subsection{Morphological characterization}

The hollow fiber cross-section and surface morphologies were investigated by scanning electron microscopy (SEM) (Quanta 600 and Zeiss Merlin), using a voltage of $3 \mathrm{kV}$ and a working distance of $3 \mathrm{~mm}$. For the SEM imaging, the samples were freeze-dried to guarantee a complete water removal without any structure collapse. To investigate the cross-section, the hollow fibers were fractured in liquid nitrogen. Finally, a $3 \mathrm{~nm}$ iridium coating was applied by sputtering onto the membrane for charging reduction.

The Cryo-SEM was carried out on a Nova Nano 630 FEI microscope to investigate the morphology of the hollow fibers in the wet state. The microscope was equipped with liquid nitrogen cryogenic system and the sample temperature was $-115{ }^{\circ} \mathrm{C}$. The imaging was performed at a voltage of 5 $\mathrm{kV}$ and $5 \mathrm{~mm}$ working distance. To prepare the sample, the hollow fibers were frozen in liquid nitrogen and fractured at $-170{ }^{\circ} \mathrm{C}$. To eliminate any condensed ice, the fracture was sublimed at $-90{ }^{\circ} \mathrm{C}$ and coated with platinum inside the cryogenic chamber.

\subsection{Solvent stability evaluation}

The solvent stability was evaluated using flat-sheet membranes. The membranes cast with different solvents were freeze-dried, weighed in an analytical balance and then immersed in $5 \mathrm{ml}$ of THF, NMP, and DMF, separately. After 10 days, the membranes were washed in methanol and freezedried again to ensure the solvent removal before the second and final weight. The solvent resistance, $O_{r}$, was finally evaluated as reported in Ref. [6] (Equation 1), where $\mathrm{m}_{1}$ is the membrane weight before the immersion, and $\mathrm{m}_{2}$ after the 10 days.

$$
O_{r}=\left[1-\left(\frac{m_{1}-m_{2}}{m_{1}}\right)\right] * 100
$$

\subsection{Dye static adsorption}

The static adsorption was evaluated using flat sheet membranes. A membrane area of $1 \mathrm{~cm}^{2}$ was accurately cut and immersed in $10 \mathrm{~mL}$ of dyes (Table 4) solution using water and ethanol as solvents. The solution concentrations were measured ahead of the membrane immersion using a UV spectrometer (NanoDrop 2000c) and a previously determined calibration curve of UV absorption as a function of concentration. The measurements were repeated every $24 \mathrm{~h}$ for 20 days until the dye adsorption on the membrane became constant. The amount of adsorbed dyes per $\mathrm{cm}^{2}$ 
of membrane was calculated, by knowing the difference between the concentrations before and after the membrane immersion in the $10 \mathrm{~mL}$ dye solution.

\subsection{X-ray diffraction analysis}

The cellulose degree of crystallinity and its polyform type were investigated using a Bruker D8 Advance diffractometer with $\mathrm{Cu}-\mathrm{K} \alpha$ radiation source at $40 \mathrm{kV}$ and $40 \mathrm{mV}$. The diffraction data were measured in the range of $5^{\circ}$ to $50^{\circ}$. The tests were done using flat sheet membranes. The crystallinity index (CI) was calculated using Equation 2, first proposed by Segal et al. [60] and further used by Chukwuemeka et al. [61] to compare the crystallinity of cellulose samples.

$$
C I=\frac{I_{002}-I_{a m}}{I_{002}} * 100
$$

where $\mathrm{I}_{002}$ is the maximum intensity of the peak corresponding to $2 \theta=22^{\circ}$ for Cellulose II and $2 \theta$ $=22.7^{\circ}$ for Cellulose $\mathrm{I}$, respectively, and $\mathrm{I}_{\mathrm{am}}$ is the intensity of the diffraction related to the amorphous region $\left(2 \theta=18^{\circ}\right.$ for Cellulose II and $2 \theta=16^{\circ}$ for Cellulose I).

\subsection{Performance}

Pure solvent permeations were measured after immersing the module into the permeating solvent for a period of up to 24 hours. A filtration setup was used to pump the feed in a crossflow mode, measuring the amount of permeate at fixed time intervals. The membrane permeation was measured using a single hollow fiber module. A transmembrane pressure of 0.2 bar was provided by a peristaltic pump and regulated by a valve in the downstream section. All the experiments were performed at room temperature.

The permeances were calculated using Equation 3:

$$
J=\frac{Q}{A \Delta P}
$$

where $\mathrm{Q}$ is the permeation rate $\left(\mathrm{L} \mathrm{h}^{-1}\right), \mathrm{A}$ is the filtration area $\left(\mathrm{m}^{2}\right)$, and $\Delta \mathrm{P}$ is the transmembrane pressure (bar), and the effective area is $A=\pi D L, \mathrm{D}$ being the outer diameter of the single fiber (m) and $\mathrm{L}$ is the fiber length (m).

For rejection measurements, dyes, PEG and PS were used as testing solutes. In the case of dyes separation, $200 \mathrm{ml}$ of the same solutions of the static adsorption were used as feed. To evaluate the dyes separation performances and exclude the effect of the solute adsorption, the retentate 
concentration was carefully measured and the permeate was collected first when no decreasing feed concentration was observed. $1 \mathrm{~g} / \mathrm{L}$ PEG feed solutions in water were prepared using different molecular weights $(0.4,1.5,10$ and $35 \mathrm{~kg} / \mathrm{mol})$. The rejection was evaluated by Equation 4 :

$$
R(\%)=100 *\left(1-\frac{C_{p}}{C_{f}}\right)
$$

where $C p$ and $C f$ are the solutes concentrations in the permeate and feed solutions respectively. The molecular weight cut-off (MWCO) is defined as the lowest molecular weight that can be $90 \%$ rejected by the membrane. The concentrations were analyzed in two different ways. In the case of linear, uncharged and colorless molecules, gel permeation chromatography was used with an Agilent refractive index detector and water as a mobile phase at $35^{\circ} \mathrm{C}$. For dyes molecules, an UV spectrometer (NanoDrop 2000c) at different wavelengths was used instead.

\subsection{Dynamic mechanical analysis (DMA)}

The mechanical characterization was performed on a Q800 Dynamic Mechanical Analyzer in the tensile mode. For this measurement, hollow fibers of about $2 \mathrm{~cm}$ were fixed on clamps. The stressstrain analyses were carried out at a constant temperature of $25^{\circ} \mathrm{C}$ using a force rate of $0.1 \mathrm{~N} / \mathrm{m}$ in a range of 0 to $18 \mathrm{~N}$.

\subsection{Zeta potential}

The zeta potential of the membranes was measured in aqueous solutions with $\mathrm{pH} \mathrm{7,} \mathrm{using} \mathrm{a}$ Zetasizer Nano series HT.

\section{Results and discussion}

Cellulose solubilization tests were successfully performed in each of the four ILs reported in Table 1. Additional tests were performed in 1-butyl-3-methylimidazolium bis(trifluoromethylsulfonyl) imide, 1-butyl-3-methylimidazolium thiocyanate, 1-ethyl-3-methylimidazolium hexafluorophosphate, 1-hexyl-3-methylimidazolium chloride, 1-methyl-3-propylimidazolium hexafluorophosphate, 1-methylimidazolium hydrogen sulfate, and 1-n-hexyl-3methylimidazolium hexafluorophosphate, however without leading to a solubilization. 


\subsection{Flat sheet membranes}

The four solutions in Table 1 were used for casting flat-sheet membranes, followed by phase inversion in a water bath. Only the first three solvents led to a self-standing membrane. Although [EMIM] $[\mathrm{Cl}]$ can dissolve cellulose in a relatively high concentration $[4,32]$, a stable membrane could not be obtained.

The goal of this work was the preparation of hollow fiber membranes. Initially, flat-sheet membranes were prepared to evaluate crystallinity, organic resistance, zeta potential, and susceptibility to dyes adsorption, as discussed below. The results obtained for flat-sheet membranes could be extended to hollow fibers prepared under analogous conditions (same solvent and temperature for phase inversion in water). A detailed performance investigation was conducted for the hollow fibers as later discussed.

\subsubsection{Crystallinity}

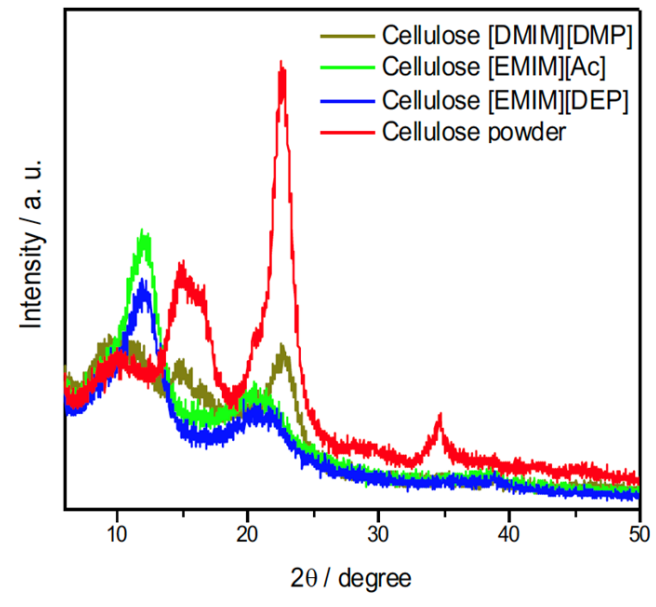

(a)


Figure 1. (a) XRD analysis of native cellulose powder and membranes cast from solutions in [EMIM][Ac], [EMIM][DEP] and [DMIM][DMP]; (b) Photographs of the corresponding cellulose casting solutions.

Figure 1 shows the XRD profiles of raw cellulose and membranes obtained with the ILs after the non-solvent induced phase separation. They reveal different cellulose polymorphs. The pattern of the raw cellulose (red line) and the membrane prepared from solutions in [DMIM][DMP] (dark 
green line) displayed a sharp peak at $2 \theta=22.7^{\circ}$ and weaker peaks at $2 \theta=15^{\circ}$ and $16.5^{\circ}$, typical of the Cellulose I [8]. The calculated crystallinity index for this system was $46 \%$, and as expected it was lower than for the native cellulose powder. The high crystallinity, which is not fully disrupted by [DMIM][DMP], could explain why the respective cellulose casting solution is turbid, compared with the analogous solutions in $[E M I M][A c]$ and $[E M I M][D E P]$. No previously reported cellulose membrane, prepared by phase inversion, had this polymorph. Figure 1 also shows the profiles of the membranes prepared from solutions in [EMIM][Ac] and [EMIM][DEP] in light green and blue lines, respectively, with peaks at $2 \theta=12.3^{\circ}, 20.5^{\circ}, 22$, which are typical of Cellulose II $[10,62]$. This polymorph type is more commonly observed after treatments, such as dissolution, regeneration or chemical modification and is characterized by higher thermodynamic stability than Cellulose I. The crystallinity indexes, in this case, are $32 \%$ and $30 \%$ for the membranes prepared from solutions in [EMIM][DEP] and [EMIM][Ac], respectively.

Moreover, the x-ray analysis helps to explain the results of the organic resistance analysis, as shown below.

\subsubsection{Organic solvent resistance}

Figure 2 shows the resistance of the flat-sheet membranes towards the most common and aggressive organic solvents: NMP, DMF, and THF. The membrane with the same polymorph of the native cellulose is the most robust. As in the case of the native cellulose, this is due to the strong hydrogen bonding formed at the inter and intramolecular level. These strong interactions guarantee that even though the organic solvent would be able to penetrate the structure, it would only cause swelling, but not dissolution [63, 64]. Cellulose II is as well able to form hydrogen bonds, which help the membranes to keep an adequate resistance towards the solvents. The higher solubility in NMP or DMF of membranes prepared from solutions in [EMIM][Ac] is strictly connected to the acetylation of the cellulose $[6,65,66]$. The acetylation partially disrupts the cellulose-cellulose hydrogen bonds and facilitated the contact with the solvents, separating the polymer chains. 


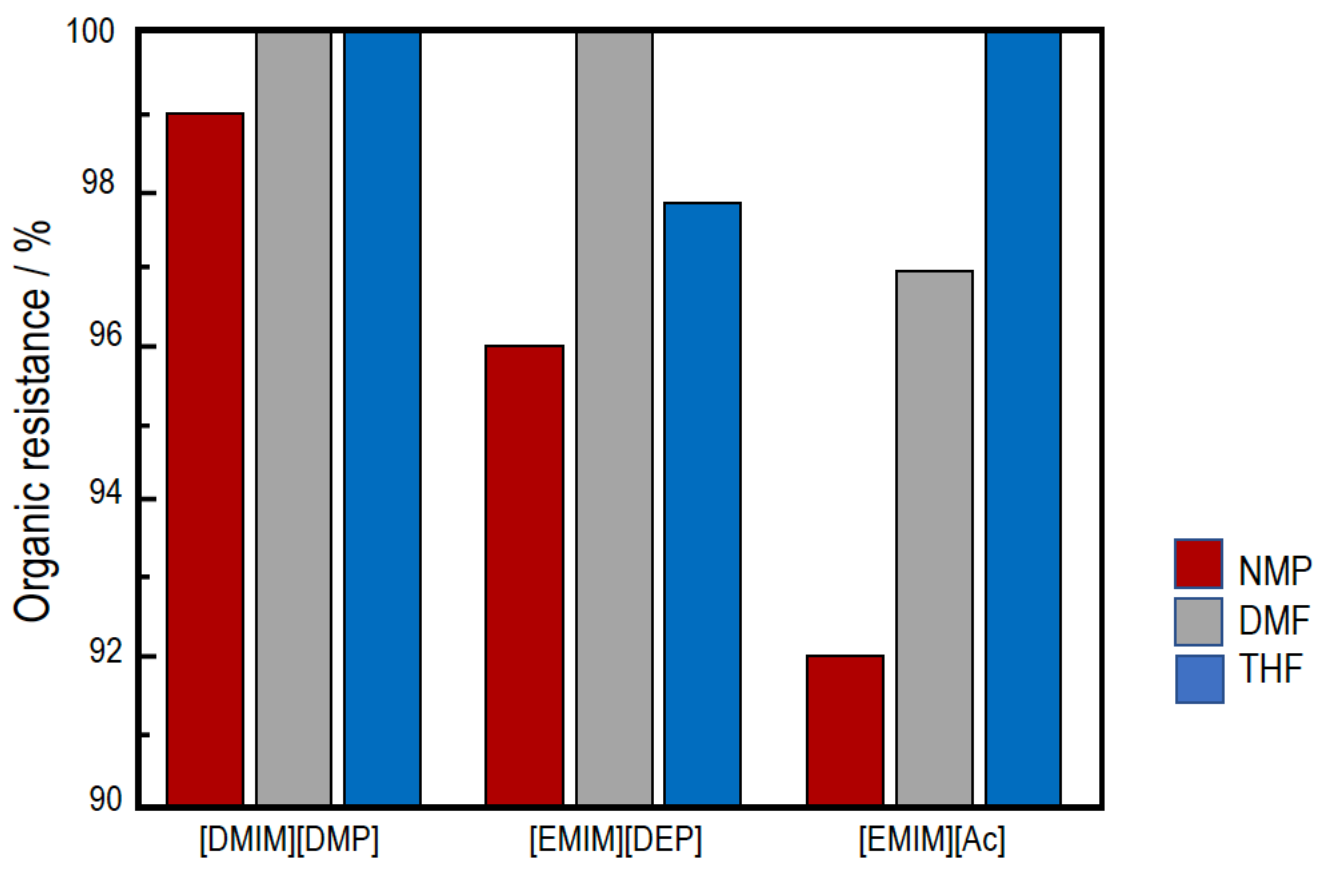

Figure 2. Organic solvent resistance of membranes prepared from solutions in [DMIM][DMP], [EMIM][DEP] and [EMIM][Ac], respectively.

\subsubsection{Dyes adsorption}

Since hydrogen bonds might also lead to dye adsorption and masquerade the rejection and MWCO results, a static absorbance analysis was carried out with dyes solutions in both water and ethanol. These experiments gave an indication if the rejection is purely due to a size exclusion molecular sieving or to a high affinity between the dyes and the membranes. The tested dyes were negatively (Congo Red, Reactive Green) and positively (Safranin O) charged, to compare the effect of the charge interactions. Brilliant blue $\mathrm{R}$ has two negative sulfonic groups as well as one positively charged protonated nitrogen atom per molecule. 


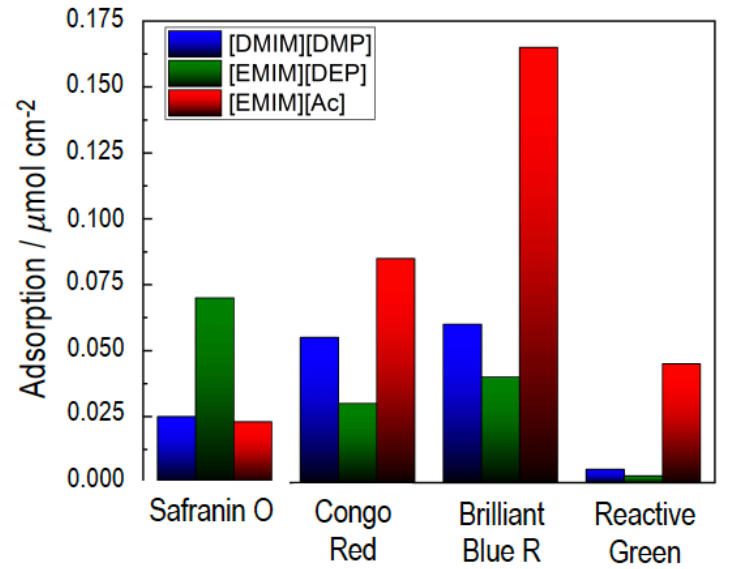

(a)

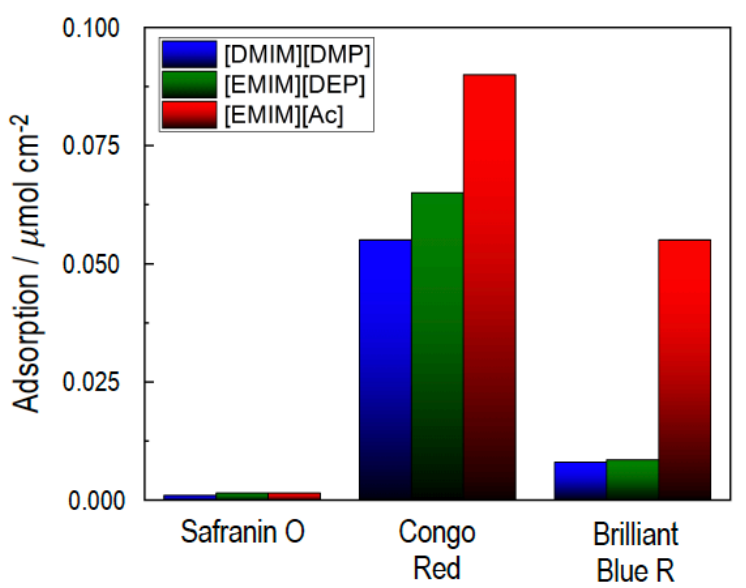

(b)

Figure 3. Static adsorption of dyes on cellulose membranes in (a) water and (b) in ethanol.

Table 2. Zeta potential values of the membranes measured in aqueous solutions at $\mathrm{pH} 7$.

\begin{tabular}{ccc}
\hline & pH 7 & \\
\hline Cellulose/[EMIM][Ac] & Cellulose/[EMIM][DEP] & Cellulose/[DMIM][DMP] \\
-36.06 & -42.1 & -27.46 \\
\hline
\end{tabular}

Table 2 reports the values of zeta potential for different membranes. The membrane surfaces are negatively charged, independently of the solvent used for the preparation. As reported in Figure 3, the highest adsorption takes place in aqueous solutions. Adsorption is a surface effect. It is strongly influenced by the charge interaction between the dyes and the cellulose surface, as well as by the hydrogen bond formation between dyes and cellulose. The slightly positively charged Safranin O has strong adsorption on cellulose in aqueous solutions, but in ethanol the adsorption is neglectable. The dielectric constant of ethanol is 3 times smaller than that of water. The dissociation of dyes molecules and the effective charge effect is therefore much more pronounced in water than in ethanol.

The adsorption of Brilliant Blue R, containing both sulfonic groups and a protonated nitrogen atom is less pronounced in ethanol but remains substantial, especially on membranes cast from solutions in $[\mathrm{EMIM}][\mathrm{Ac}]$. The adsorption of the negatively charged Congo Red is strong in water and ethanol. The charge effect alone cannot explain the behavior of these two dyes. Hydrogen bonding must be the predominant factor. Cellulose is known for its large density of hydrogen bonds. The 
hydroxyl groups in cellulose are hydrogen bond donors, due to the proton bonded to the electronegative oxygen atom, and at the same time, they can act as hydrogen bond acceptors, due to the available electron pairs in the oxygen. As mentioned before, the spontaneous hydrogen bond formation strongly contributes to the insolubility of cellulose and its stability in most solvents. But the hydroxyl groups also provide sites for hydrogen bond formation with dyes, leading to a partially irreversible adsorption. Primary and secondary amino groups, respectively present in Congo Red and Brilliant Blue R, can also act as both hydrogen bond donor or acceptor and easily attach to the cellulose surface. The primary amines in Congo Red are even more effective in the adsorption[67]. The sulfonic groups in both dyes can act as proton acceptors [68], forming then hydrogen bonds with the cellulose hydroxyl groups. Practically no adsorption reduction is observed in this case when changing from water to ethanol.

When comparing membranes obtained from solutions in different ionic liquids, those prepared from a solution in [EMIM][Ac] had the strongest adsorption. It is known that partial acetylation takes place when cellulose is heated in [EMIM][Ac] [69]. The acetate group is not a hydrogen bond donor, due to the lack of an acidic proton. It is a relatively weak hydrogen bond acceptor. The ester groups as hydrogen bond acceptors seem to favor the interaction with the primary amino groups in Congo Red and the secondary amino groups in Brilliant Blue R as hydrogen bond donors. The intensity of cellulose-cellulose hydrogen bond is higher in the case of the membranes prepared with other ionic liquids. This explains why the membranes made from solutions in [EMIM][Ac] are less resistant to the organic solvents since the interchain disruption would be easier.

\subsection{Hollow fiber membranes}

\subsubsection{Morphology}

Hollow fiber membranes were spun, following the conditions listed in Table 1. The morphology of the fibers was investigated by SEM. The SEM images are shown in Figure 4. The hollow fibers are free of macrovoids. Although they were prepared with the same spinneret and same weight \% of cellulose in solution, the diameter of the dry fibers obtained from different ionic liquids is clearly different. The fiber obtained from [EMIM][DEP] has the largest diameter, while those obtained from $[\mathrm{EMIM}][\mathrm{Ac}]$ or $[\mathrm{DMIM}][\mathrm{DMP}]$ are much more compact. At high magnification, a morphology with wrinkles can be seen with the smallest features for that prepared from [EMIM][Ac]. Interstitial paths in the wrinkles could be responsible for the transport of water and 
linear molecules, such as PEG, during the filtration experiments. However, another possibility is that the observed wrinkles would be formed by drying during the sample preparation for SEM. To clarify if the morphology of the dry membranes is the same as that in water or another filtration medium, which would be more relevant for the real application, cryo-SEM images were obtained of wet membranes after immersion in water. The cross-section cryo-SEM images are reported in Figure 5. At a low magnification, we confirm that the membrane prepared from [EMIM][DEP] is the one with the largest diameter. The big difference can be seen at high magnification. The detailed cryo-SEM images of the fibers cross-sections are clearly different than those of the corresponding dry fibers. No wrinkles are observed, but a fine porosity is seen. The membrane prepared from [EMIM][DEP] is the densest one, while those prepared from [EMIM][Ac] and [DMIM][DMP] are more porous with more open pores.

$[\mathrm{EMIM}][\mathrm{Ac}]$

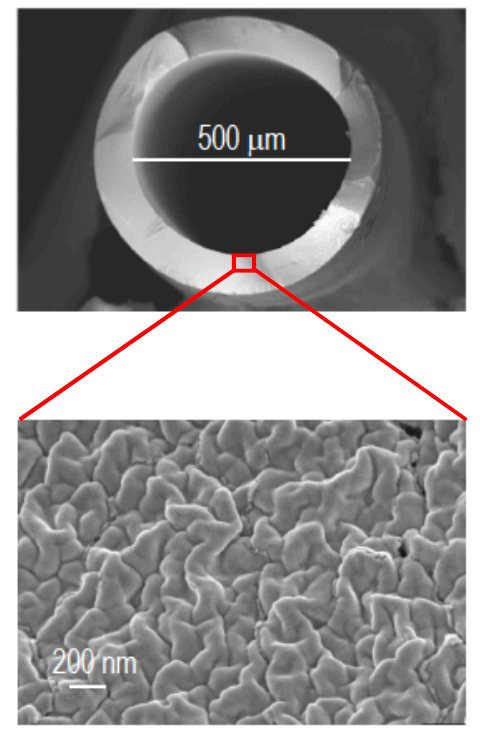

(a)
[EMIM][DEP]

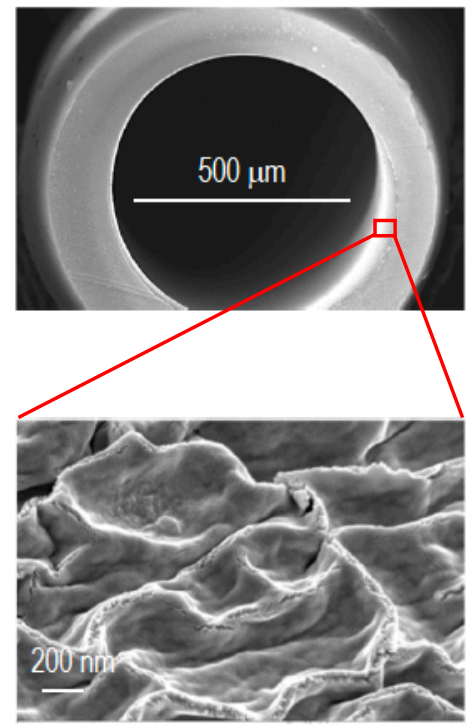

(b)
[DMIM][DMP]

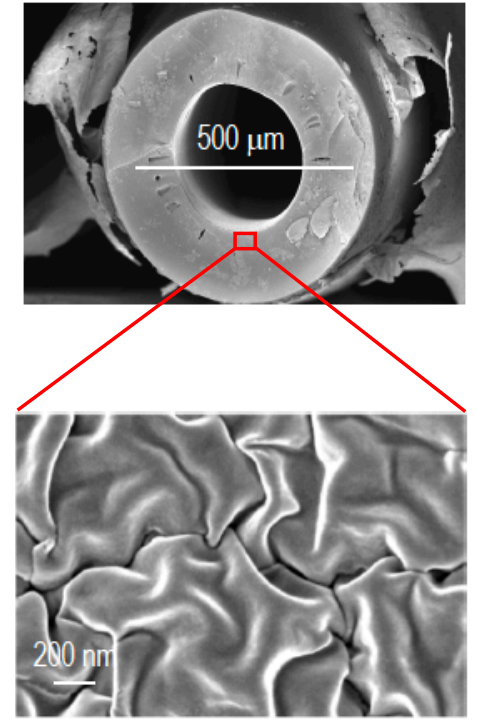

(c)

Figure 4. Cross-section SEM images (room temperature) of hollow fibers prepared from cellulose solutions in (a) [EMIM][Ac], (b) [EMIM][DEP] and (c) [DMIM][DMP] with low (top) and high (bottom) magnifications. 


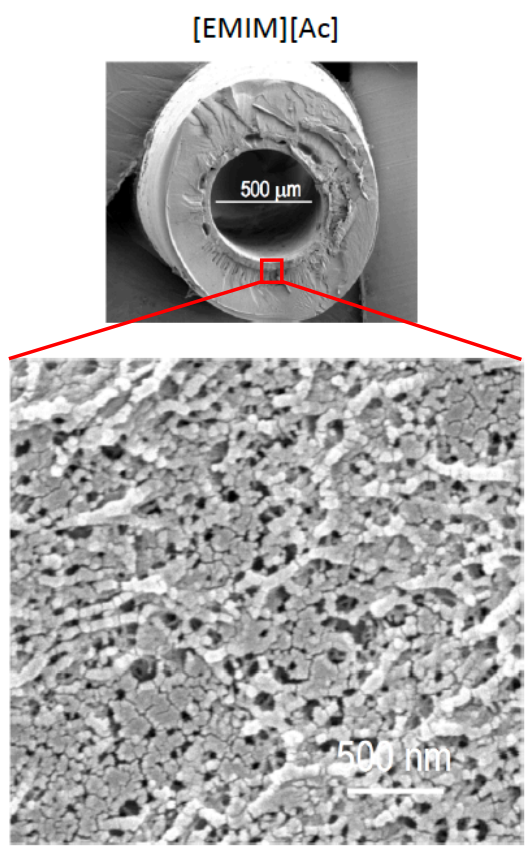

(a)

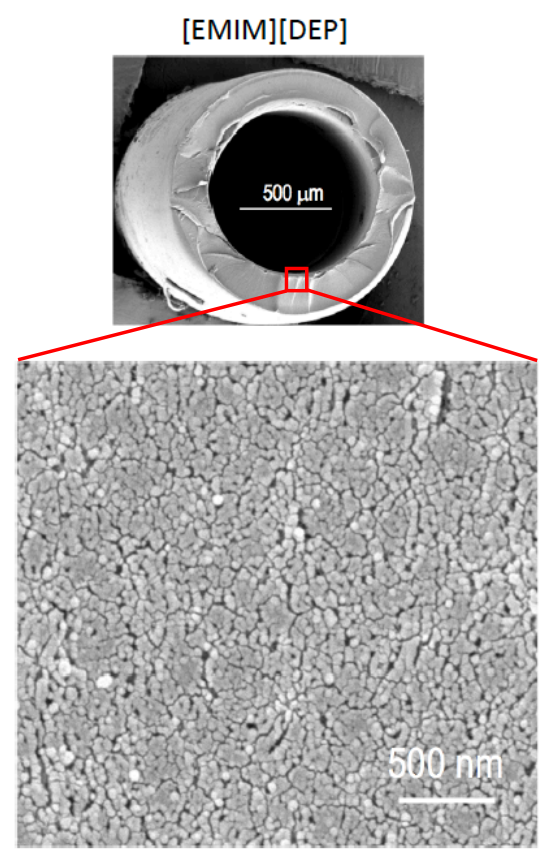

(b)



(c)

Figure 5. Cross-section cryo-SEM images of hollow fibers prepared from cellulose solutions in (a) $[\mathrm{EMIM}][\mathrm{Ac}]$, (b) $[\mathrm{EMIM}][\mathrm{DEP}]$ and (c) [DMIM][DMP] with low (top) and high (bottom) magnifications.

\subsubsection{Performance}

The permeation of the different hollow fiber membranes to pure water, ethanol, and DMF was investigated in cross-flow experiments, and the results are listed in Table 3 and Figure S1. The results of analogous measurements performed with dyes solutions are shown in the supplementary information (Figures S2-S4). The permeation of a hollow fiber prepared from solutions in [EMIM][Ac] was clearly higher than of others, and this can be explained by the more open structure seen in Figure 5a. The rejections of the membranes were evaluated first using PEG solutions in water. These are neutral linear molecules with molecular weights $0.4,1.5,10$, and 35 $\mathrm{kg} / \mathrm{mol}$. The experiments were also performed in cross-flow cells, and the results are shown in Figure 6a. The MWCOs are all in the ultrafiltration range. The hollow fiber membrane with the lowest MWCO $(18 \mathrm{~kg} / \mathrm{mol})$ was prepared from solutions in [EMIM][DEP]. They have the densest 
porous structure, as shown in Figure 5b. Cellulose/[EMIM][Ac] hollow fibers had a MWCO of $23 \mathrm{~kg} / \mathrm{mol}$ and the cellulose/[DMIM][DMP] ones had a MWCO higher than $35 \mathrm{~kg} / \mathrm{mol}$.

Table 3. Permeation of hollow fiber membranes prepared from cellulose in different ionic liquids as solvents.

\begin{tabular}{cccc}
\hline \multirow{3}{*}{ Permeant } & \multicolumn{3}{c}{ Permeation $\left(\mathrm{L} \mathrm{m}^{-2} \mathrm{~h}^{-1} \mathrm{bar}^{-1}\right)$} \\
\cline { 2 - 4 } & $48 \pm 3$ & Cellulose solvent \\
\cline { 2 - 4 } & $19 \pm 1$ & $8 \pm 2$ & {$[3 \pm 2$} \\
Water & $44 \pm 9$ & $6 \pm 1$ & $6 \pm 1$ \\
Ethanol & {$[$ EMIM][Ac] } & $7 \pm 1$ & $8 \pm 2$ \\
DMF & & & DEIM] \\
\hline
\end{tabular}

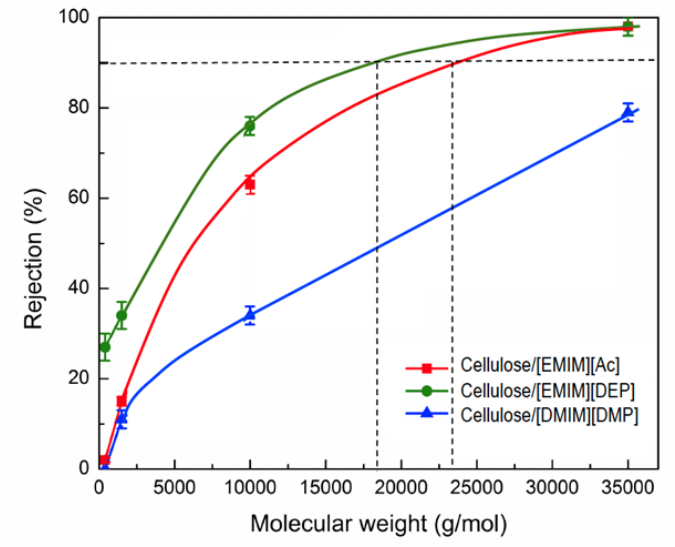

(a)

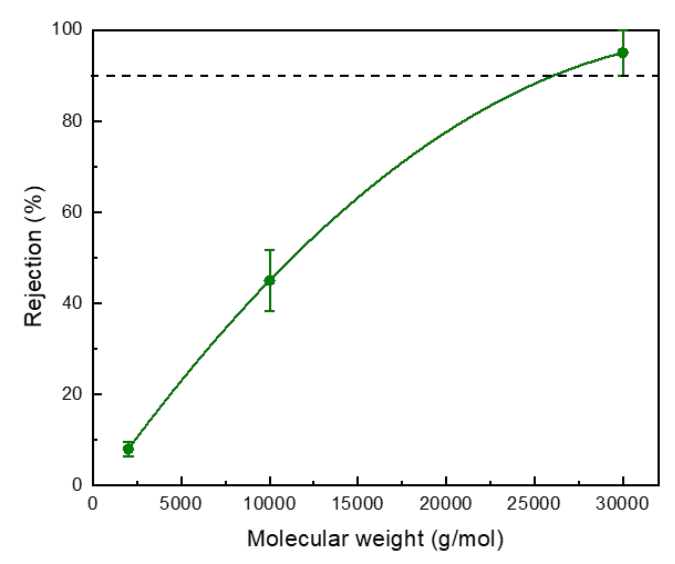

(b)

Figure 6. Rejection performance of cellulose hollow fibers: (a) rejection of PEG with different molecular weights $(0.4,1.5,10$, and $35 \mathrm{~kg} / \mathrm{mol})$ in water for fibers prepared from different ILs; (b) rejection of PS with different molecular weights $(2,10$ and $30 \mathrm{~kg} / \mathrm{mol})$ in DMF for fibers prepared from solutions in [EMIM][DEP].

The permeation and retention of molecules with various molecular weights indicate the hollow fiber membranes capability of separation, controlled by size sieving. However, the linearity of the 
PEG molecules might masquerade the exact pore size determination since their molecular reptation into nanopores cannot be excluded. An additional factor that can also influence the PEG transport is its interaction with the hydrated cellulose. Moreover, in the fully swollen condition, the cellulose chains have higher mobility, leading to a decrease of the glass transition temperature below ambient temperature $[67,70]$. All these aspects together could contribute to the rejection of PEG's linear molecules, which could diffuse through the amorphous part of the cellulose. For this reason, we additionally investigated the performance of the hollow fibers for rejecting PS, which is a macromolecule with aromatic repeating unities, with much weaker interaction with cellulose. We present here the results for the hollow fibers prepared from solutions in [EMIM][DEP], chosen because they were the ones with the best MWCO measured using PEG in water. The experiments were performed with PS solutions in DMF (Figure 6b), leading to a MWCO around $25 \mathrm{~kg} / \mathrm{mol}$. This is even higher than the value measured with PEG in water $(18 \mathrm{~kg} / \mathrm{mol})$. PEG is reported to adsorb on cellulose $[71,72]$, through the terminal groups, which have a basic character. If some adsorption occurs, an effective reduction of the pore diameters could lead to a slightly higher rejection (lower MWCO). The basicity effect is more pronounced for lower molecular weights [73], promoting even higher difference in rejection values for PEG and PS of similar molecular weights in the range of $10 \mathrm{~kg} \mathrm{~mol}^{-1}$ or below.

The filtration and rejection tests were further performed with non-linear small molecules. Dyes are available in different sizes in the nanofiltration range (Table 4), however a careful analysis of their permeation results is necessary. In the nanofiltration range, the transport might be a combination of pore flow and solution-diffusion [74]. Parallel to the size effect, the dyes affinity with cellulose promoted by polarity and hydrogen bonding, and the Donnan effect caused by the charged molecules might enhance or hinder the transport through the membrane. In addition, a potential adsorption on the cellulose must be carefully taken into consideration. In aqueous solution, the best separation performance was again achieved with the cellulose/[EMIM][DEP] membrane, which was the densest, followed by cellulose/[DMIM][DMP] membranes. They succeeded in rejecting more than $90 \%$ of all negative dyes (Figure $7 \mathrm{~b}$ ), while the cellulose/[EMIM][Ac] hollow fiber membrane was able to exclude Reactive Green $\left(1418 \mathrm{~g} \mathrm{~mol}^{-1}\right)$ and Congo Red $\left(696 \mathrm{~g} \mathrm{~mol}^{-1}\right)$ but not Brilliant Blue R (826 $\mathrm{g} \mathrm{mol}^{-1}$ ) (Figure 7a). A low rejection of the positively charged Safranin $O$ was measured for all membranes, which are negatively charged (Table 2). Safranin $O$ is also the smallest dye investigated in this work ( $350 \mathrm{~g} \mathrm{~mol}^{-1}$, Table 4). 


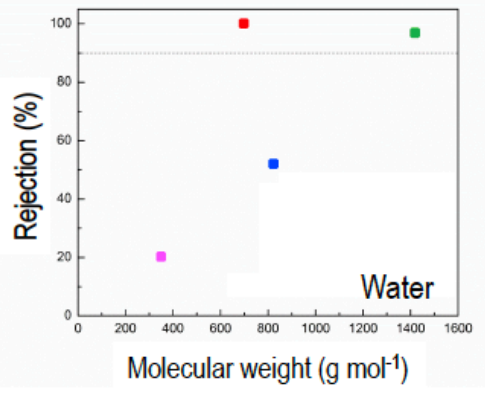

(a) $[\mathrm{EMIM}][\mathrm{Ac}]$

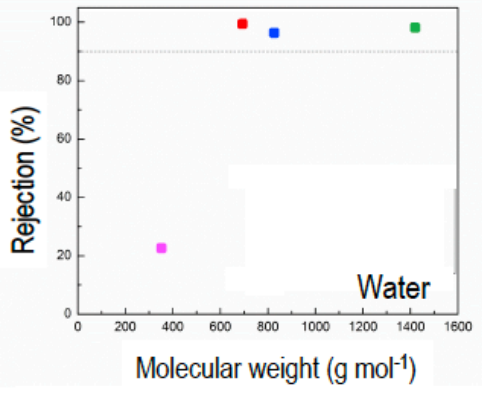

(b) $[\mathrm{EMIM}][\mathrm{DEP}]$

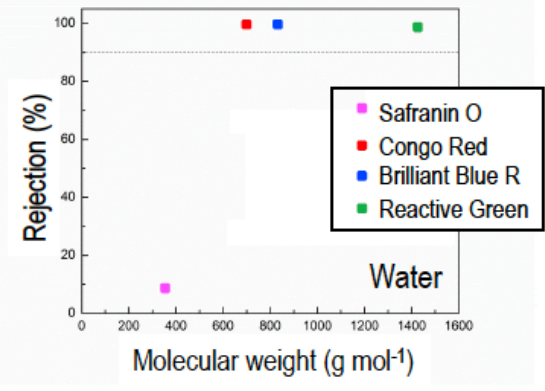

(c) $[\mathrm{EMIM}][\mathrm{DMP}]$

Figure 7. Dyes rejection of hollow fiber membranes, prepared from cellulose solutions in (a) [EMIM][Ac], (b) [EMIM][DEP], and (c) [DMIM][DMP]. Rejection measured after 24 hours filtration with dyes dissolved in water.



(a) $[\mathrm{EMIM}][\mathrm{Ac}]$

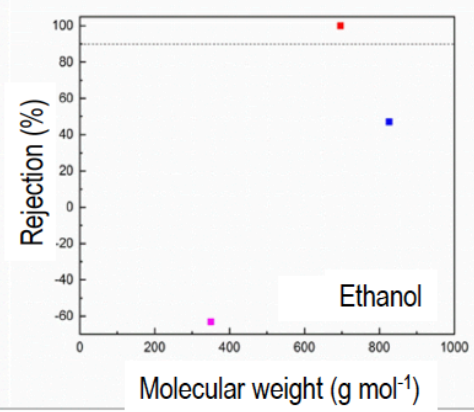

(b) $[\mathrm{EMIM}][\mathrm{DEP}]$

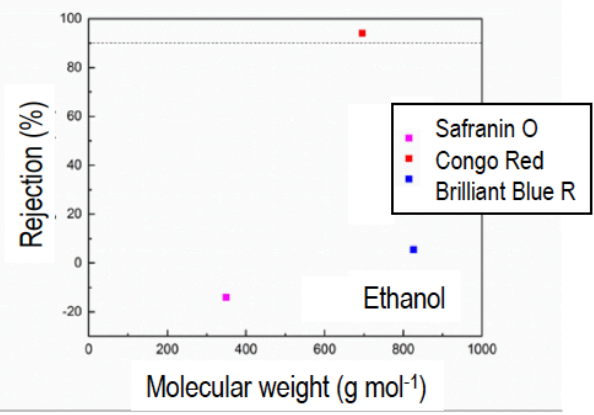

(c) $[\mathrm{EMIM}][\mathrm{DMP}]$

Figure 8. Dyes rejection of hollow fiber membranes, prepared from cellulose solutions in (a) [EMIM][Ac], (b) [EMIM][DEP], and (c) [DMIM][DMP]. Rejection measured after 24 hours filtration with dyes dissolved in ethanol.

In ethanol, the best separation performance was again achieved with cellulose/[EMIM][DEP] and cellulose/[DMIM][DMP] membranes, which were able to reject more than $90 \%$ Congo Red, as reported in Figure 8b and 8c, respectively. Despite the higher molecular weight, Brilliant Blue R was not rejected with the same efficiency by the membranes (Figures 8). Figure 3 shows that the adsorption of Congo Red is much stronger than of Brilliant Blue R. The higher affinity between the cellulose and Congo Red is due to the positions and space between the functional groups, sterically matching the functionality in the cellulose. As it has already been reported by other groups, direct dyes can strongly form hydrogen bonding with the cellulosic substrate [67] [75]. 
The amino groups in the Congo Red are spaced at intervals corresponding to the distance of hydroxyl groups of the cellulose $[67,68]$. This favors the dye adsorption on the membrane surface. The rejection was measured after 24 hours of constant exposure to the dye and we assumed that the adsorption of the dyes was not an ongoing process anymore. But the irreversible adsorption on the membrane probably contributed to the apparent high rejection of Congo Red compared with Brilliant Blue R, despite of its lower molecular weight. The cellulose/[EMIM][Ac] membrane, which is the most open with transport properties predominately following a pore-flow and sieving mechanism, does not reject the negative dyes (Figure 8a) with size as high as $1418 \mathrm{~g} \mathrm{~mol}^{-1}$. Membranes prepared from cellulose/[EMIM][DEP] and cellulose-[DMIM][DMP] (Figure 8b and 8c) had negative rejections of Safranin O. Negative rejection is a known phenomenon in dye filtration with organic media, and other groups were able to explain it using Hildebrand solubility parameter [76]. Cellulose is a semi-crystalline polymer. In water or other polar solvents, the amorphous segments of cellulose are plasticized and swell. The transport through the cellulose membranes takes place through the plasticized flexible and amorphous portions. A transport mechanism based on the classical solution-diffusion might be able to describe the negative rejection [74]. Table 4 lists the contributions to the Hansen solubility parameters due to dispersive forces, polarity and H-bonds formation (Equation 5). The value of $\mathrm{R}_{\mathrm{a}}$, calculated by Equation 6 is an indication of the affinity between the permeants and cellulose. Higher $\mathrm{R}_{\mathrm{a}}$ values correspond to lower affinity. $\delta$ values for cellulose from two different sources are presented and $\mathrm{R}_{\mathrm{a}}$ were calculated for both set of values, as well as the $\delta$ values for acetylated cellulose. According to the Ra values, the affinities of water and ethanol to cellulose are similar and high. The affinity of Safranin $\mathrm{O}$ with cellulose is the lowest one $\left(\mathrm{R}_{\mathrm{a}}=33(\mathrm{MPa})^{1 / 2}\right)$. Therefore, the solubility factor using the solution-diffusion model would not explain the negative rejection, i. e. a preferential Safranin O transport through the membrane relative to ethanol. A possible explanation can be found by considering the water-cellulose and ethanol-cellulose H-bonds formation. Dyes transported through water-swollen cellulose are exposed to both $\mathrm{OH}$ groups of cellulose and $\mathrm{OH}$ groups of the water partially bonded to the polymer by H-bond. In the case of cellulose membranes swollen by ethanol, the H-bond between ethanol and cellulose is similarly strong, however we can figure out that a molecular orientation takes place. The H-bond between ethanol and cellulose shields its hydroxyl groups from the exposure to the permeating dyes. Safranin O molecules in an ethanol solution might be exposed to the less polar part of the ethanol (Figure 9). By the principle 
of independent surface action, we can consider that each part of the ethanol molecule has a local surface free energy. While the hydroxyl groups have surface energies around $190 \mathrm{ergs} / \mathrm{cm}^{2}$, when the hydrocarbon part is exposed, the energy drops down to $50 \mathrm{ergs} / \mathrm{cm}^{2}$ or less $[77,78]$. The environment seen by the Safranin O molecules could be analogous to that of a hydrocarbon polymer like polyethylene, which has similar $\delta$ values, and therefore implying larger solubility (estimated $\mathrm{R}_{\mathrm{a}}=5.3(\mathrm{MPa})^{1 / 2}$, based on polyethylene) than in cellulose solved by water. Higher solubility would promote the permeation by the solution-diffusion transport model. Membranes prepared from [EMIM][Ac] are at least partially acetylated and have less $\mathrm{OH}$ available for interaction with water. The values for cellulose acetate are also shown in Table 4 . The $\mathrm{R}_{\mathrm{a}}$ value with Brilliant Blue would decrease from 24.9 (cellulose) to 11.8 (cellulose acetate) (MPa) ${ }^{1 / 2}$, explaining the lower rejection in aqueous solutions in Figure 7a.

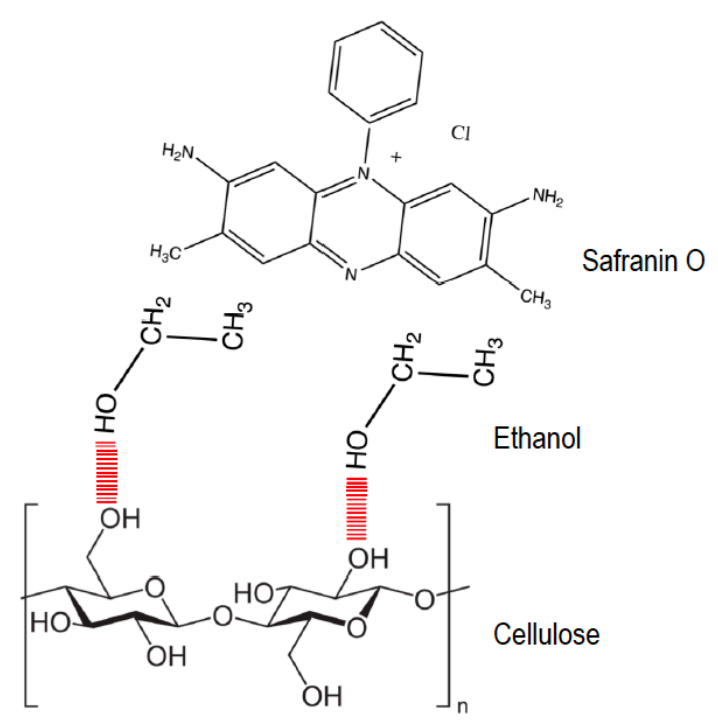

Figure 9. Hydrogen bond between cellulose and ethanol and exposure to Safranin O. 
Table 4. Dyes properties [79, 80]

\begin{tabular}{|c|c|c|c|c|c|c|}
\hline & \multirow{2}{*}{$\begin{array}{c}\text { MW } \\
(\mathrm{g} / \mathrm{mol}) \\
\text { Charge }\end{array}$} & \multirow[t]{2}{*}{ Dye structure } & \multicolumn{4}{|c|}{$\begin{array}{l}\text { Hansen solubility parameters } \\
\qquad(\mathrm{MPa})^{1 / 2}\end{array}$} \\
\hline & & & $\delta_{\mathrm{D}}$ & $\delta_{\mathrm{P}}$ & $\delta_{\mathrm{H}}$ & $\mathrm{R}_{\mathrm{a}}$ \\
\hline \multirow[t]{2}{*}{ Cellulose } & & & 12.7 & 19.4 & 31.3 & \\
\hline & & & 6.8 & 15.8 & 24.8 & \\
\hline Cellulose & & & 14.9 & 7.1 & 11.1 & \\
\hline \multicolumn{7}{|l|}{ acetate } \\
\hline Water & & & 15.5 & 16 & 42.3 & 12.8 \\
\hline Ethanol & & & 15.5 & 8.8 & 19.4 & 14.7 \\
\hline Reactive & 1418 & & & & & \\
\hline Green & Negative & & & & & \\
\hline Brilliant & 826 & & 18.6 & 14.2 & 17 & 19.2 \\
\hline Blue & Negative & & & & & 24.9 \\
\hline Congo Red & 696 & & 17.9 & 22.1 & 25.7 & 12.2 \\
\hline & Negative & & & & & 23.1 \\
\hline Safranin O & 350 & & 20.1 & 5.1 & 8.5 & 30.7 \\
\hline & Positive & & & & & 33.0 \\
\hline
\end{tabular}

Each $\delta$ contribution (dispersive, polar and H-bond) is in part estimated using the HSPiP software [79]; the cohesive energy $\delta^{2}$ equal to

$\delta^{2}=\delta_{D}^{2}+\delta_{P}^{2}+\delta_{H}^{2}$

$R_{a}=\left[4\left(\delta_{D, \text { cellulose }}-\delta_{D, \text { permeant }}\right)^{2}+\left(\delta_{P, \text { cellulose }}-\delta_{P, \text { permeant }}\right)^{2}+\left(\delta_{H, \text { cellulose }}-\delta_{H, \text { permeant }}\right)^{2}\right]^{0.5}$ 


\subsubsection{Mechanical properties}

Besides the performance in terms of permeation and selectivity, the mechanical stability of a membrane is an important factor for applications. The hollow fiber mechanical properties were investigated by dynamic mechanical analysis and are reported in Figure 10 and Table 5. Toughness, Young's modulus and elongating at break were all determined by stress-strain experiments. All membranes exhibited similar behavior when in the dry state. The Young's modulus was calculated as the slope of the linear section of the stress-strain line, while the toughness by integrating the total area below the curve. Table 5 shows that the highest toughness was measured for the cellulose/[EMIM][DEP] hollow fibers, which also had the highest elongation at break and Young's modulus. The lowest values were obtained for the cellulose/[EMIM[Ac] hollow fibers.

Table 5. Mechanical properties of cellulose membranes prepared from solutions in different ionic liquids.

\begin{tabular}{lccc}
\hline & \multicolumn{3}{c}{ Membrane dried after swelling in water } \\
\cline { 2 - 4 } & {$[\mathrm{EMIM}][\mathrm{Ac}]$} & {$[\mathrm{EMIM}][\mathrm{DEP}]$} & {$[\mathrm{DMIM}][\mathrm{DMP}]$} \\
\hline Young modulus (MPa) & 21 & 31 & 23 \\
Toughness (GPa) & 1 & 74 & 10 \\
Elongation at break (\%) & 12 & 36 \\
\hline
\end{tabular}

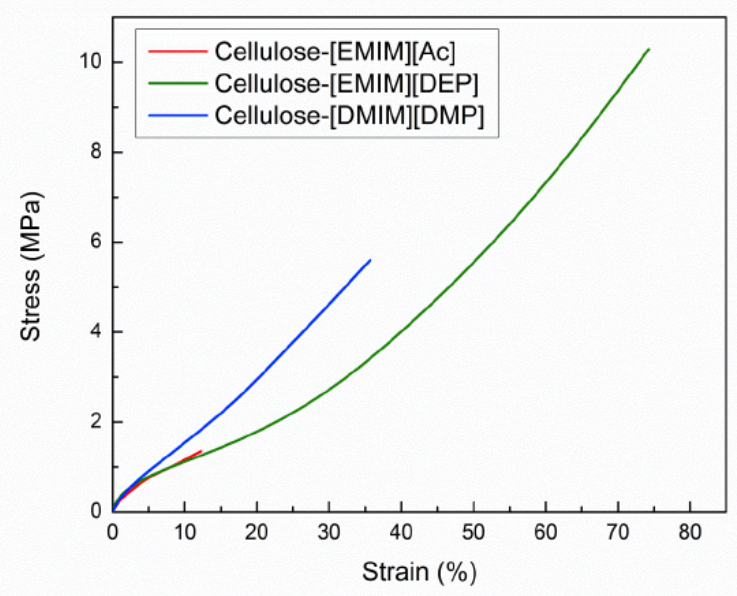

(a)

Figure 10. Stress-strain mechanical analysis of the hollow fibers spun from solutions in different ionic liquids. 


\section{Conclusion}

Cellulose hollow fibers were successfully prepared via spinning technique using three different ionic liquids as solvent. Cellulose I polymorph was obtained with [DMIM][DMP], and Cellulose II was obtained with [EMIM][Ac] and [EMIM][DEP]. Membranes prepared from solutions in [DMIM][DMP] had slightly higher resistance towards organic solvents such as NMP, THF, and DMF, followed by [EMIM][DEP] and [EMIM][Ac] .

Cryo-SEM images showed differences in porosity between the hollow fiber membranes. In aqueous media a complete rejection of all the negatively charged dyes, Congo Red, Brilliant Blue $\mathrm{R}$ and Reactive Green was achieved by preparing hollow fiber membranes from solutions in [DMIM][DMP] and [EMIM][DEP], while hollow fiber prepared from [EMIM][Ac] rejected only Congo Red and Reactive Green. The highest water permeances was obtained for cellulose/[EMIM[Ac], which is $48 \mathrm{~L} \mathrm{~m}^{-2} \mathrm{~h}^{-1} \mathrm{bar}^{-1}$.

In organic solvents, the best membrane performances were achieved for the hollow fibers obtained from [DMIM][DMP] and [EMIM][DEP]. The rejection of the negatively charged Congo Red (696 $\left.\mathrm{g} \mathrm{mol}^{-1}\right)$ was higher than $90 \%$. In opposite, the rejection of the much smaller $\left(350 \mathrm{~g} \mathrm{~mol}^{-1}\right)$ and positive dye Safranin $\mathrm{O}$ was negative. The negative rejection is explained by assuming a solutiondiffusion mechanism and taking into consideration the solubility of the dyes into the membrane. The rejection is highly dependent on the affinity between the membrane and solute and not only on the solute size.

The mechanical analysis showed that the membranes prepared with [EMIM][DEP] had the highest toughness and this combined with the good filtration performance makes them the best candidates to be used for separations in organic solvents.

\section{Acknowledgments}

The work was sponsored by the King Abdullah University of Science and Technology, grant REP/1/3848-01-01 and URF134410101.

\section{Annex A. Supporting Information}


Membrane permeances to pure DMF and to dyes solution in water and ethanol.

\section{References}

[1] D. Klemm, B. Heublein, H.P. Fink, A. Bohn, Cellulose: fascinating biopolymer and sustainable raw material, Angewandte Chemie International Edition, 44 (2005) 3358-3393.

[2] F. Yang, L. Li, Q. Li, W. Tan, W. Liu, M. Xian, Enhancement of enzymatic in situ saccharification of cellulose in aqueous-ionic liquid media by ultrasonic intensification, Carbohydrate Polymers, 81 (2010) 311-316.

[3] S. Kobayashi, J. Sakamoto, S. Kimura, In vitro synthesis of cellulose and related polysaccharides, Progress in polymer science, 26 (2001) 1525-1560.

[4] L. Feng, Z.-1. Chen, Research progress on dissolution and functional modification of cellulose in ionic liquids, Journal of Molecular Liquids, 142 (2008) 1-5.

[5] E. Kontturi, P. Laaksonen, M.B. Linder, A.H. Gröschel, O.J. Rojas, O. Ikkala, Advanced materials through assembly of nanocelluloses, Advanced Materials, (2018) 1703779.

[6] S. Livazovic, Z. Li, A.R. Behzad, K.-V. Peinemann, S.P. Nunes, Cellulose multilayer membranes manufacture with ionic liquid, Journal of Membrane Science, 490 (2015) 282-293.

[7] K.M. Gupta, J. Jiang, Cellulose dissolution and regeneration in ionic liquids: A computational perspective, Chemical Engineering Science, 121 (2015) 180-189.

[8] J. Zhao, Y. Zhao, Z. Wang, Z. Peng, Effect of polymorphs of cellulose nanocrystal on the thermal properties of poly (lactic acid)/cellulose nanocrystal composites, The European Physical Journal E, 39 (2016) 118.

[9] F. Ibrahim, M. Moniruzzaman, S. Yusup, Y. Uemura, Dissolution of cellulose with ionic liquid in pressurized cell, Journal of Molecular Liquids, 211 (2015) 370-372.

[10] D. Zhao, H. Li, J. Zhang, L. Fu, M. Liu, J. Fu, P. Ren, Dissolution of cellulose in phosphate-based ionic liquids, Carbohydrate Polymers, 87 (2012) 1490-1494.

[11] B. Medronho, B. Lindman, Competing forces during cellulose dissolution: from solvents to mechanisms, Current Opinion in Colloid \& Interface Science, 19 (2014) 32-40.

[12] B. Medronho, B. Lindman, Brief overview on cellulose dissolution/regeneration interactions and mechanisms, Advances in colloid and interface science, 222 (2015) 502-508.

[13] B. Medronho, A. Romano, M.G. Miguel, L. Stigsson, B. Lindman, Rationalizing cellulose (in) solubility: reviewing basic physicochemical aspects and role of hydrophobic interactions, Cellulose, 19 (2012) 581-587.

[14] M. Ghasemi, M. Tsianou, P. Alexandridis, Assessment of solvents for cellulose dissolution, Bioresource technology, 228 (2017) 330-338.

[15] L. Alves, B. Medronho, F.E. Antunes, D. Topgaard, B. Lindman, Dissolution state of cellulose in aqueous systems. 2. Acidic solvents, Carbohydrate polymers, 151 (2016) 707-715.

[16] S. Liu, J. Zeng, D. Tao, L. Zhang, Microfiltration performance of regenerated cellulose membrane prepared at low temperature for wastewater treatment, Cellulose, 17 (2010) 1159-1169.

[17] H.-J. Li, Y.-M. Cao, J.-J. Qin, X.-M. Jie, T.-H. Wang, J.-H. Liu, Q. Yuan, Development and characterization of anti-fouling cellulose hollow fiber UF membranes for oil-water separation, Journal of Membrane science, 279 (2006) 328-335.

[18] T. Nishino, I. Matsuda, K. Hirao, All-cellulose composite, Macromolecules, 37 (2004) 7683-7687.

[19] K. Edgar, K. Arnold, W. Blount, J. Lawniczak, D. Lowman, Synthesis and properties of cellulose acetoacetates, Macromolecules, 28 (1995) 4122-4128.

[20] T. Puspasari, N. Pradeep, K.-V. Peinemann, Crosslinked cellulose thin film composite nanofiltration membranes with zero salt rejection, Journal of Membrane Science, 491 (2015) 132-137.

[21] C. Olsson, G. Westman, Direct dissolution of cellulose: background, means and applications, (2013).

[22] T. Liebert, Cellulose solvents-remarkable history, bright future, in: Cellulose solvents: for analysis, shaping and chemical modification, ACS Publications, 2010, pp. 3-54. 
[23] M. Buonomenna, J. Bae, Organic solvent nanofiltration in pharmaceutical industry, Separation \& Purification Reviews, 44 (2015) 157-182.

[24] C. Capello, U. Fischer, K. Hungerbühler, What is a green solvent? A comprehensive framework for the environmental assessment of solvents, Green Chemistry, 9 (2007) 927-934.

[25] J.M. DeSimone, Practical approaches to green solvents, Science, 297 (2002) 799-803.

[26] K.R. Seddon, Ionic liquids for clean technology, Journal of Chemical Technology \& Biotechnology: International Research in Process, Environmental AND Clean Technology, 68 (1997) 351-356.

[27] R.D. Rogers, K.R. Seddon, Ionic liquids--solvents of the future?, Science, 302 (2003) 792-793.

[28] M.J. Earle, K.R. Seddon, Ionic liquids. Green solvents for the future, Pure and applied chemistry, 72 (2000) 1391-1398.

[29] R.A. Sheldon, Green solvents for sustainable organic synthesis: state of the art, Green Chemistry, 7 (2005) 267-278.

[30] G. Charles, Cellulose solution, (1934).

[31] R.P. Swatloski, S.K. Spear, J.D. Holbrey, R.D. Rogers, Dissolution of cellose with ionic liquids, Journal of the American chemical society, 124 (2002) 4974-4975.

[32] A. Pinkert, K.N. Marsh, S. Pang, M.P. Staiger, Ionic liquids and their interaction with cellulose, Chemical reviews, 109 (2009) 6712-6728.

[33] P. Mäki-Arvela, I. Anugwom, P. Virtanen, R. Sjöholm, J.-P. Mikkola, Dissolution of lignocellulosic materials and its constituents using ionic liquids - a review, Industrial Crops and Products, 32 (2010) 175201.

[34] O. Stolarska, A. Pawlowska-Zygarowicz, A. Soto, H. Rodríguez, M. Smiglak, Mixtures of ionic liquids as more efficient media for cellulose dissolution, Carbohydrate polymers, 178 (2017) 277-285.

[35] H. Zhang, J. Wu, J. Zhang, J. He, 1-Allyl-3-methylimidazolium chloride room temperature ionic liquid: a new and powerful nonderivatizing solvent for cellulose, Macromolecules, 38 (2005) 8272-8277.

[36] T. Puspasari, K.-V. Peinemann, Application of thin film cellulose composite membrane for dye wastewater reuse, Journal of Water Process Engineering, 13 (2016) 176-182.

[37] X.-L. Li, L.-P. Zhu, B.-K. Zhu, Y.-Y. Xu, High-flux and anti-fouling cellulose nanofiltration membranes prepared via phase inversion with ionic liquid as solvent, Separation and purification technology, 83 (2011) 66-73.

[38] F. Sukma, P. Çulfaz-Emecen, Cellulose membranes for organic solvent nanofiltration, Journal of Membrane Science, 545 (2018) 329-336.

[39] D.Y. Xing, N. Peng, T.-S. Chung, Investigation of unique interactions between cellulose acetate and ionic liquid [EMIM]SCN, and their influences on hollow fiber ultrafiltration membranes, Journal of Membrane Science, 380 (2011) 87-97.

[40] S.-P. Sun, S.-Y. Chan, W. Xing, Y. Wang, T.-S. Chung, Facile Synthesis of Dual-Layer Organic Solvent Nanofiltration (OSN) Hollow Fiber Membranes, ACS Sustainable Chemistry \& Engineering, 3 (2015) 3019-3023.

[41] S.-P. Sun, S.-Y. Chan, T.-S.J.C.E.S. Chung, A slow-fast phase separation (SFPS) process to fabricate dual-layer hollow fiber substrates for thin-film composite (TFC) organic solvent nanofiltration (OSN) membranes, 129 (2015) 232-242.

[42] D. Kim, S. Livazovic, G. Falca, S.P. Nunes, Oil-Water Separation using Membranes Manufactured from Cellulose/Ionic Liquid Solutions, ACS Sustainable Chemistry \& Engineering, 7 (2019) 5649-5659.

[43] X. Jie, Y. Cao, B. Lin, Q. Yuan, Gas permeation performance of cellulose hollow fiber membranes made from the cellulose/N-methylmorpholine-N-oxide/H2O system, Journal of applied polymer science, 91 (2004) 1873-1880.

[44] X. Jie, Y. Cao, J.-J. Qin, J. Liu, Q. Yuan, Influence of drying method on morphology and properties of asymmetric cellulose hollow fiber membrane, Journal of membrane science, 246 (2005) 157-165.

[45] F. Mashkoor, A. Nasar, A.M. Asiri, Exploring the Reusability of Synthetically Contaminated Wastewater Containing Crystal Violet Dye using Tectona grandis Sawdust as a Very Low-Cost Adsorbent, Scientific reports, 8 (2018) 8314.

[46] R. Kant, Textile dyeing industry an environmental hazard, Natural science, 4 (2012) 22-26. 
[47] A.K. Verma, R.R. Dash, P. Bhunia, A review on chemical coagulation/flocculation technologies for removal of colour from textile wastewaters, Journal of environmental management, 93 (2012) 154-168.

[48] V. Katheresan, J. Kansedo, S.Y. Lau, Efficiency of Various Recent Wastewater Dye Removal Methods: A Review, Journal of Environmental Chemical Engineering, (2018).

[49] P. Marchetti, M.F. Jimenez Solomon, G. Szekely, A.G. Livingston, Molecular separation with organic solvent nanofiltration: a critical review, Chemical reviews, 114 (2014) 10735-10806.

[50] P. Vandezande, L.E. Gevers, I.F. Vankelecom, Solvent resistant nanofiltration: separating on a molecular level, Chemical Society Reviews, 37 (2008) 365-405.

[51] J. da Silva Burgal, L.G. Peeva, S. Kumbharkar, A. Livingston, Organic solvent resistant poly (etherether-ketone) nanofiltration membranes, Journal of membrane science, 479 (2015) 105-116.

[52] K. Hendrix, M. Van Eynde, G. Koeckelberghs, I.F. Vankelecom, Crosslinking of modified poly (ether ether ketone) membranes for use in solvent resistant nanofiltration, Journal of membrane science, 447 (2013) 212-221.

[53] Y.S. Toh, F. Lim, A. Livingston, Polymeric membranes for nanofiltration in polar aprotic solvents, Journal of Membrane Science, 301 (2007) 3-10.

[54] K. Vanherck, P. Vandezande, S.O. Aldea, I.F. Vankelecom, Cross-linked polyimide membranes for solvent resistant nanofiltration in aprotic solvents, Journal of Membrane Science, 320 (2008) 468-476.

[55] H. Mariën, I.F. Vankelecom, Transformation of cross-linked polyimide UF membranes into highly permeable SRNF membranes via solvent annealing, Journal of Membrane Science, 541 (2017) 205-213.

[56] I.B. Valtcheva, P. Marchetti, A.G. Livingston, Crosslinked polybenzimidazole membranes for organic solvent nanofiltration (OSN): Analysis of crosslinking reaction mechanism and effects of reaction parameters, Journal of Membrane Science, 493 (2015) 568-579.

[57] I.B. Valtcheva, S.C. Kumbharkar, J.F. Kim, Y. Bhole, A.G. Livingston, Beyond polyimide: crosslinked polybenzimidazole membranes for organic solvent nanofiltration (OSN) in harsh environments, Journal of Membrane Science, 457 (2014) 62-72.

[58] S. Chisca, G. Falca, V.E. Musteata, C. Boi, S.P. Nunes, Crosslinked polytriazole membranes for organophilic filtration, Journal of Membrane Science, 528 (2017) 264-272.

[59] B. Pulido, S. Chisca, S.P. Nunes, Solvent and thermal resistant ultrafiltration membranes from alkynefunctionalized high-performance polymers, Journal of Membrane Science, 564 (2018) 361-371.

[60] L. Segal, J. Creely, A. Martin Jr, C. Conrad, An empirical method for estimating the degree of crystallinity of native cellulose using the X-ray diffractometer, Textile Research Journal, 29 (1959) 786794.

[61] C.P. Azubuike, H. Rodríguez, A.O. Okhamafe, R.D. Rogers, Physicochemical properties of maize cob cellulose powders reconstituted from ionic liquid solution, Cellulose, 19 (2012) 425-433.

[62] M.-C. Li, Q. Wu, K. Song, S. Lee, Y. Qing, Y. Wu, Cellulose nanoparticles: structure-morphologyrheology relationships, ACS Sustainable Chemistry \& Engineering, 3 (2015) 821-832.

[63] K.M. Gupta, Z. Hu, J. Jiang, Cellulose regeneration from a cellulose/ionic liquid mixture: the role of anti-solvents, RSC Advances, 3 (2013) 12794-12801.

[64] G. Mantanis, R. Young, R. Rowell, Swelling of compressed cellulose fiber webs in organic liquids, Cellulose, 2 (1995) 1-22.

[65] T. Heinze, S. Dorn, M. Schöbitz, T. Liebert, S. Köhler, F. Meister, Interactions of ionic liquids with polysaccharides-2: Cellulose, in: Macromolecular Symposia, Wiley Online Library, 2008, pp. 8-22.

[66] B. Lindman, G. Karlström, L. Stigsson, On the mechanism of dissolution of cellulose, Journal of Molecular Liquids, 156 (2010) 76-81.

[67] P. Brady, Diffusion of dyes in natural fibres, Review of Progress in Coloration and Related Topics, 22 (1992) 58-78.

[68] H. Puchtler, F. Sweat, M. Levine, On the binding of Congo red by amyloid, Journal of Histochemistry \& Cytochemistry, 10 (1962) 355-364.

[69] S.K. Karatzos, L.A. Edye, R.M. Wellard, The undesirable acetylation of cellulose by the acetate ion of 1-ethyl-3-methylimidazolium acetate, Cellulose, 19 (2012) 307-312. 
[70] L. Szcześniak, A. Rachocki, J. Tritt-Goc, Glass transition temperature and thermal decomposition of cellulose powder, Cellulose, 15 (2008) 445-451.

[71] D. Cheng, Y. Wen, L. Wang, X. An, X. Zhu, Y. Ni, Adsorption of polyethylene glycol (PEG) onto cellulose nano-crystals to improve its dispersity, Carbohydrate polymers, 123 (2015) 157-163.

[72] G.F. de Lima, A.G. de Souza, D.S. Rosa, Effect of adsorption of polyethylene glycol (PEG), in aqueous media, to improve cellulose nanostructures stability, Journal of Molecular Liquids, 268 (2018) 415-424.

[73] P. Sakellariou, M. Abraham, G. Whiting, Solubility characteristics of poly (ethylene oxide): Effect of molecular weight, end groups and temperature, Colloid and Polymer Science, 272 (1994) 872-875.

[74] P. Marchetti, A.G. Livingston, Predictive membrane transport models for Organic Solvent Nanofiltration: How complex do we need to be?, Journal of Membrane Science, 476 (2015) 530-553.

[75] P.J. Wood, Specificity in the interaction of direct dyes with polysaccharides, Carbohydrate research, 85 (1980) 271-287.

[76] H.B. Soltane, D. Roizard, E. Favre, Study of the rejection of various solutes in OSN by a composite polydimethylsiloxane membrane: Investigation of the role of solute affinity, Separation and Purification Technology, 161 (2016) 193-201.

[77] I. Langmuir, The distribution and orientation of molecules, in: Third Colloid Symposium Monograph, Chemical Catalog Company New York, 1925.

[78] A.W. Adamson, A.P. Gast, Physical chemistry of surfaces, (1967).

[79] C.M. Hansen, Hansen solubility parameters: a user's handbook, CRC press, 2002.

[80] R. Rinaldi, J.N. Reece, Solution-based Deconstruction of (Ligno)-Cellulose, in: Behrens, Malte and Abhaya Datye (eds.) Catalysis for the Conversion of Biomass and Its Derivatives., Max Planck Research Library for the History and Development of Knowledge ..., 2013. 
Supporting information

\section{Cellulose hollow fibers for organic resistant nanofiltration}

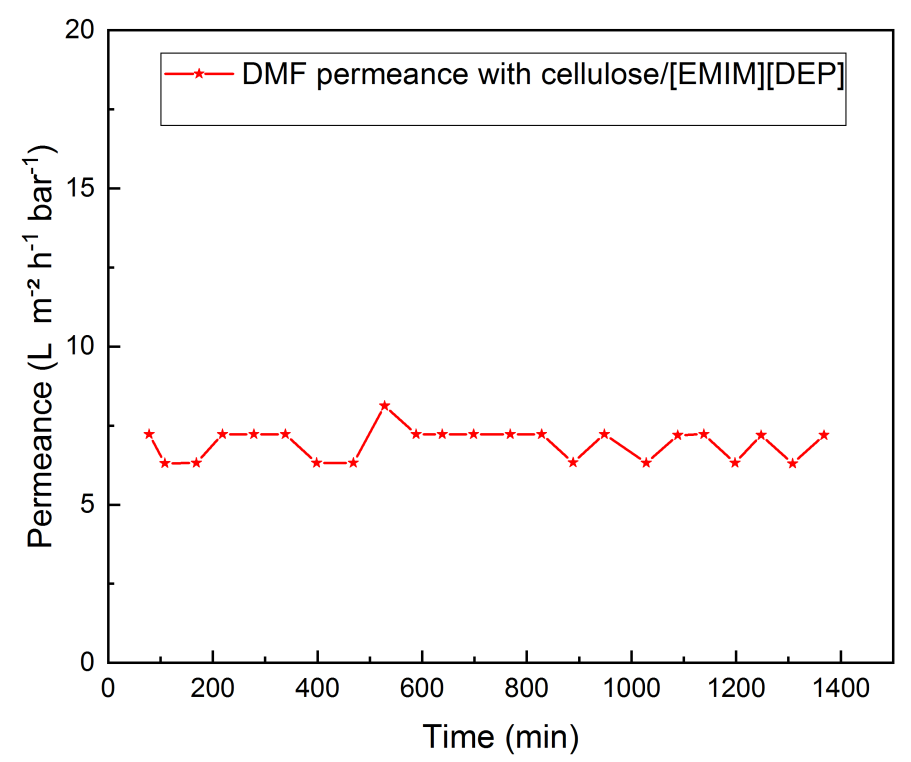

Figure S1. DMF permeance measured up to $24 \mathrm{~h}$ for hollow fibers prepared from dopes with [EMIM][DEP]. 


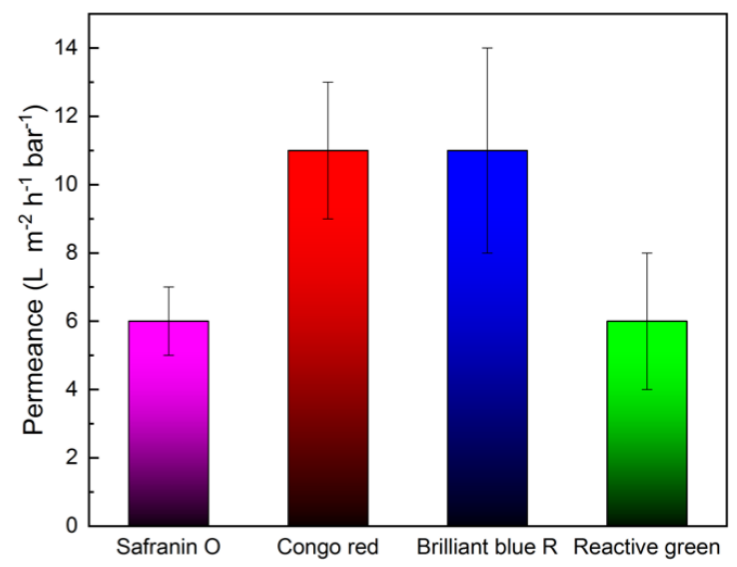

(a)

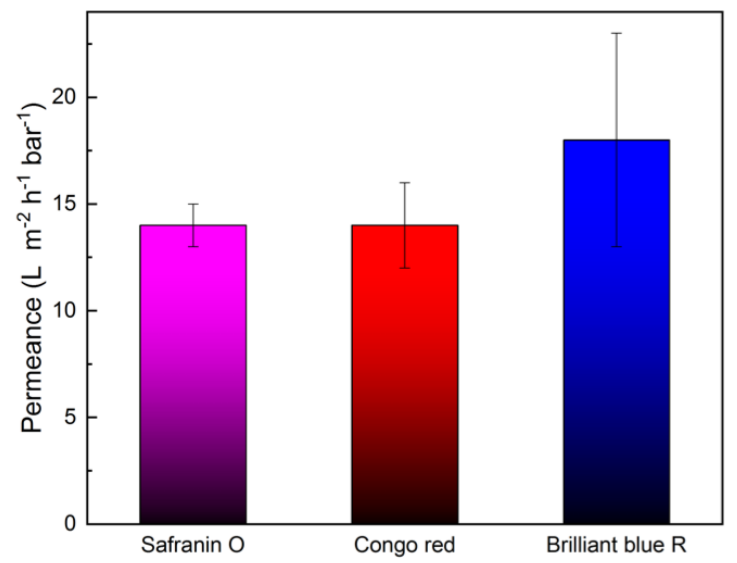

(b)

Figure S2. Cellulose/[EMIM][Ac] membrane permeation of dyes solutions (a) in water, and (b) in ethanol.

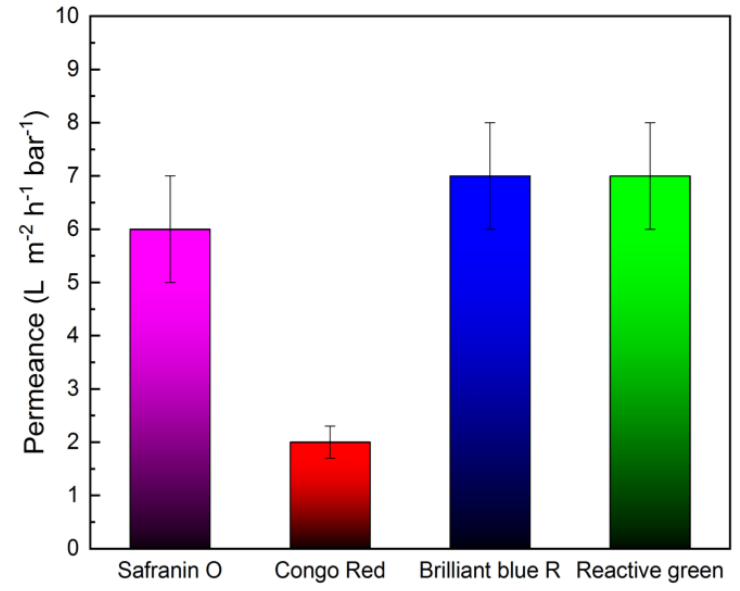

(a)

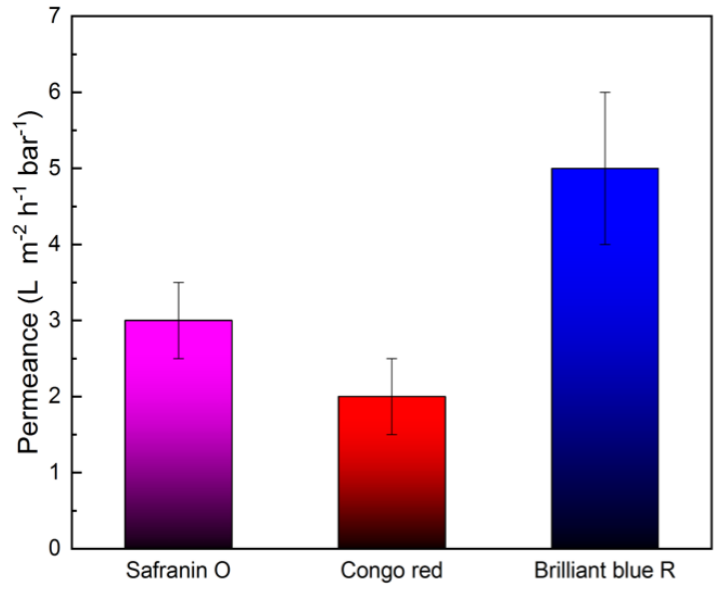

(b)

Figure S3. Cellulose/[EMIM][DEP] membrane permeation of dyes solutions (a) in water, and (b) in ethanol. 


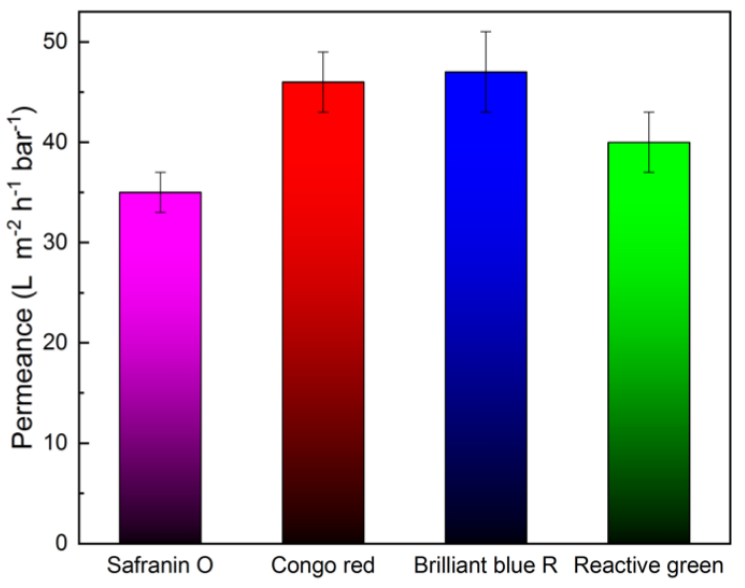

(a)

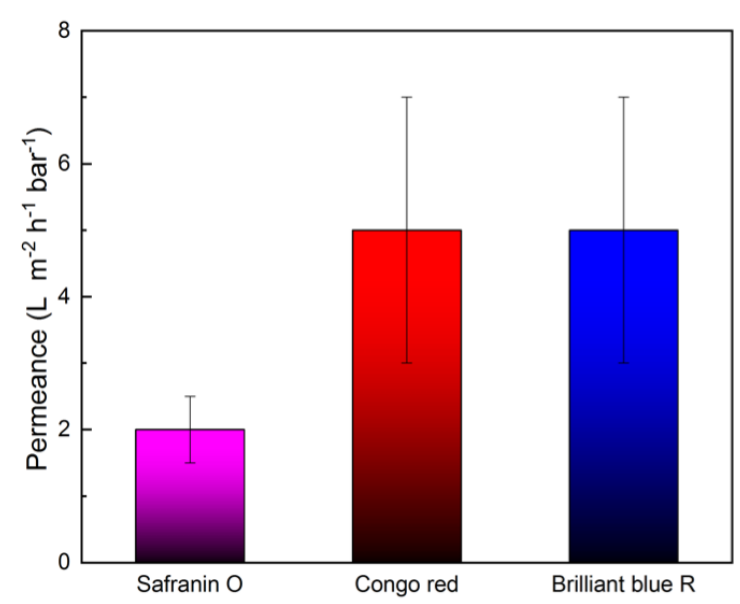

(b)

Figure S4. Cellulose/[DMIM][DMP] membrane permeation of dyes solutions (a) in water, and (b) in ethanol. 